\title{
Microgrid Restoration after Major Faults in Main Grid with Automatic and Constant Time Switching
}

\author{
Elyas Zare \\ Dept. of Electrical Engineering, Noshirvani university of Babol, Babol, Iran \\ E-mail:zare_elyas@stu.nit.ac.ir \\ Majid Shahabi \\ Dept. of Electrical Engineering, Noshirvani university of Babol, Babol, Iran \\ E-mail:shahabi.m@nit.ac.ir
}

\begin{abstract}
When a microgrid and distributed generation resources are disconnected from the grid for protection reasons, the restoration of microgrid (restoring distributed generation resources to feed the loads in microgrid) causes to increase the reliability of microgrid. When a fault occurs in the main grid, the reliability of islanded microgrid will be increased. In this paper a novel method for restoration of the microgrid is proposed when the fault occurred in the main grid. Therefore, we can take advantage of selling power energy during the fault. In addition, because of increasing in reliability, the price of energy will be increased. This paper selected a microgrid with two type of distributed generation resources, power electronic based distributed generation and small gas turbine with synchronous generator. Another purpose of this paper is to reduce restoration time. The proposed algorithm for automatic switching time is provided. This paper selected a microgrid system in medium voltage. The limitation voltage and frequency is according to IEEE 1547 standards, and simulation will be done by EMTP-RV with automatic and constant time switching separately.
\end{abstract}

Index Terms - Automatic Switching, Distributed Generation Resources, Microgrid, Restoration

\section{Introduction}

Using the distributed generators in distribution system would bring benefits for the provider companies, power consumers and in general the society [1], [2].

Reducing line failures, improving Voltage profile, reducing the pollutant gas diffusion, enabling the distribution and transfer systems capacities, postponing the investment for the network development, increasing the efficiency and security for the sensitive and significant loads of the distribution networks are among the positive impacts and consequences of distributed production (generation) for the energy and network suppliers and users [3], [4].

The microgrid concept is presented by some electrical business companies to offer some reliable solutions such as managing the loads and small resources as a separate systems and simultaneously using the heat and electricity as a part of the main grid. In a microgrid, the generators can be micro turbines, fuel cells, photovoltaic systems, traverse motors or any alternative current source with any storing devices such as fly-wheel, energy condenser and batteries. These resources can meet the needs of the local heat and produce electricity. Now, the microgrid systems have focused on the conventional and common technologies of scattered energy sources especially small gas turbine and micro turbine and in near future will be used in the advanced technologies such as fuel cells or storing systems like fly-wheel with maximum output.

The rest of the paper has been organized as follows. In Section 2, operation principles are presented. A Model of Distributed Generation and Loads are presented in Section 3; also in this section an algorithm is proposed for restoration and switching in microgrid. Simulations are given in section 4 . Simulation results in this section reveal the effectiveness of the proposed method. Finally, concluding remarks are drawn in Section 5 .

\section{Operation Principles}

In IEEE standards, the connecting mechanism for the distributed generation resources [5], [6] the information exchange, monitoring [7] and the related equipment tests are presented [8]. This study focuses on the distribution system at a medium voltage of $20 \mathrm{kv}$ along with the distributed generation resources by using the Iran's distribution system data. Figure 1 
shows part of the system that is capable of being used by $\mathrm{CB}_{2}$ and $\mathrm{CB}_{3}$ switches as microgrid. When there is a failure in the main grid, $\mathrm{CB}_{1}$ breaker will be actived. When the $\mathrm{CB}_{1}$ breaker starts operating, $\mathrm{CB}_{2}$ and $\mathrm{CB}_{3}$ receive the data and will be opened to let the microgrid operates as an island. The starting algorithm of microgrid will include the following stages:
Hv Bus Mv Bus

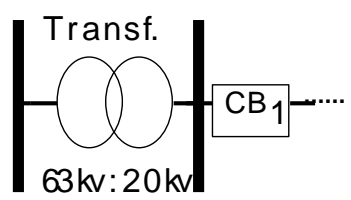

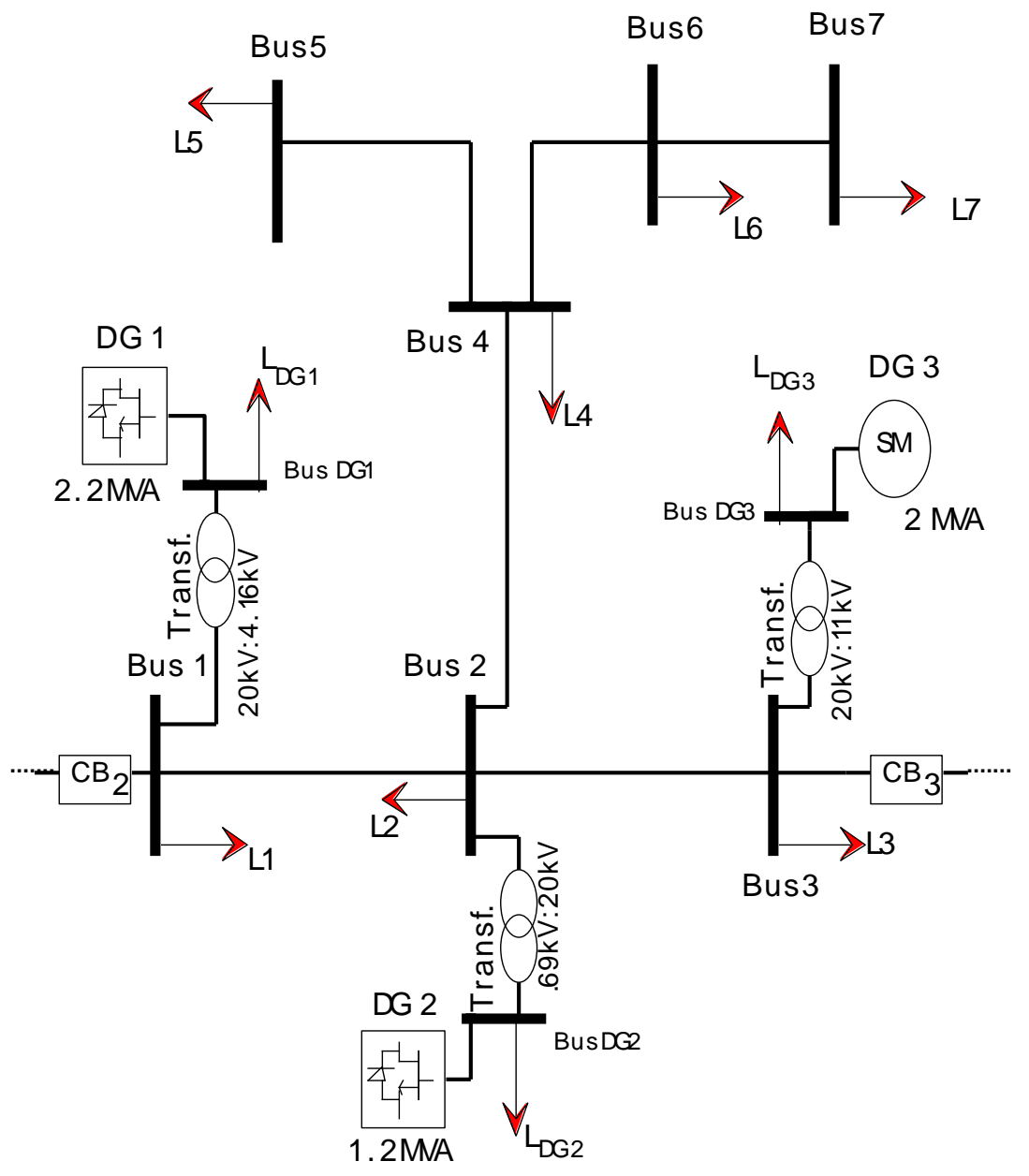

Fig. 1: Topology of Under Test Microgrid
1. Confirming the fault signal: when a fault occurs in the main grid and the $\mathrm{CB}_{1}$ starts operating, an order is sent to the microgrid central control system to make the microgrid started operating independently.

2. Disconnecting all the distributed generation resources: after facing a fault and failure, in order to protect the distributed generation resources, it is required to discharge these resources out of the system.

3. Disconnecting all the loads: in order to restore and restart the microgrid, the loads should be entered into the system based on their priority, therefore, it is necessary to discharge all the loads from the system.

4. Forming microgrid: the central controlling system would start creating the microgrid by sending an signal to the $\mathrm{CB}_{2}$ and $\mathrm{CB}_{3}$ switches.
5. Changing the controlling mode of the distributed generation resources: when the distributed generation resources are connected to the main grid, the frequency control is done by main grid, but when the microgrid works independently from the main grid, it is necessary that resources control frequency as well as the voltage.

6. Connecting the distributed generation resources in unloaded state: after the establishment of the microgrid because there is no charge or load in the microgrid, it is necessary that the resources start without any charge

7. Connecting with the emphasis on the priority of loads: the loads will enter the circuit based on their priority to let the important loads face minor failures.

8. Generating the power regarding to the connected loads: when a load enters the circuit, it will cause a voltage and frequency difference in the microgrid 
optimal conditions and the resources will make up for this difference by generating more power and will continue to operate until all the loads enter the network.

9. Using the microgrid independently form the main grid: the process of using the microgrid will continue to remove all the faults in the main grid.

10. Confirming the connection possibility: when the fault is removed from the main grid and the electricity runs through the network, an signal will be sent to the central controlling system to connect the microgrid to the main grid

11. Confirming synchronization between the main grid and microgrid: in order to connect the microgrid and main grid, it is required that the breakers make connection possible at the time when the least possible voltage difference between the microgrid and main grid occurs.

12. Connecting the microgrid and main grid: when the situation is suitable for connecting the microgrid to the main grid, the central controlling system would issue an order to close the breakers.

13. Changing the control mode of the distributed generation resources: at the connection mode of the distributed generation resources to the main grid, there will be no need to control the frequency using resources.

14. Reducing the power generation by the distributed generation resources: when using the microgrid independently, the resources have the maximum power generation, but when connecting the microgrid to the main grid there is no need to use the maximum power by the distributed generation resources.

Table 1: Loads Data

\begin{tabular}{|c|c|c|}
\hline Load name & Active power(MW) & $\cos \varphi$ \\
\hline $\mathrm{L}_{1}$ & 0.58 & 0.86 \\
\hline $\mathrm{L}_{2}$ & 0.6 & 0.82 \\
\hline $\mathrm{L}_{3}$ & 0.5 & 0.81 \\
\hline $\mathrm{L}_{4}$ & 0.45 & 0.81 \\
\hline $\mathrm{L}_{5}$ & 0.33 & 0.8 \\
\hline $\mathrm{L}_{6}$ & 0.44 & 0.82 \\
\hline $\mathrm{L}_{7}$ & 0.3 & 0.81 \\
\hline $\mathrm{L}_{\mathrm{DG} 1}$ & 0.56 & 0.85 \\
\hline $\mathrm{L}_{\mathrm{DG} 2}$ & 0.3 & 0.85 \\
\hline $\mathrm{L}_{\mathrm{DG} 3}$ & 0.45 & 0.85 \\
\hline$\Sigma \mathrm{Load}_{\mathrm{a}}$ & $\mathrm{P}=4.51 \mathrm{MW}, \mathrm{Q}=3.09 \mathrm{MVar}$ & \\
\hline
\end{tabular}

The microgrid included 7 load buses and 3 generation buses (including 1 resource and 1 load), which are connected to the main feeder by a cumulative transformer. The data related to the system under study are given in the appendix. The nominal power of loads is given in Table 1 .

\section{Model of Distributed Generation and Loads}

The under-study microgrid (Figure 1) has three distributed generation resources. The connected resources to buses 1 and 2 are the resources that have dc outputs, which are connected to the network by a power electronic converter, and the source which is connected to bus 3 is a small gas turbine with synchronous generator.

\subsection{Model of Small Gas Turbine}

The small gas turbine is considered as a distributed generation resource and its electrical part is included a synchronous machine and exciter system, the mechanical part is included governor and turbine [9].

When the microgrid is operating in connected mode, the controlling mode of small gas turbine is P-Q control and it is not its responsibility to control the voltage and frequency. But in the islanding operating mode of microgrid, the controlling mode of small gas turbine is voltage and frequency control. Table 2 and Figure 2 show the information of the synchronous machine and exciter system model to control the exciter current of the generator, respectively.

Table 2: Information of the Synchronous Machine

\begin{tabular}{|c|c|}
\hline Parameter & Accurate Value \\
\hline Nominal power (MVA) & 2 \\
\hline Nominal voltage (kV) & 11 \\
\hline Armature Resistance $\mathrm{R}_{\mathrm{a}}(\mathrm{pu})$ & 0.0036 \\
\hline distributed reactance $X_{l}(p u)$ & 0.056 \\
\hline Reactance $X_{d}(p u)$ & 1.56 \\
\hline Reactance $X_{d}^{\prime}(p u)$ & 0.295 \\
\hline Reactance $X_{\mathrm{d}}(\mathrm{pu})$ & 0.17 \\
\hline Time Constant $\mathrm{T}_{\mathrm{do}}(\mathrm{s})$ & 3.5 \\
\hline Time Constant $\mathrm{T}_{\mathrm{do}}$ (s) & 0.04 \\
\hline Reactance $\mathrm{X}_{\mathrm{q}}(\mathrm{pu})$ & 1.08 \\
\hline Reactance $X_{\mathrm{q}}^{\prime}(\mathrm{pu})$ & 0.6 \\
\hline Reactance $X_{\mathrm{q}}(\mathrm{pu})$ & 0.17 \\
\hline Time Constant $\mathrm{T}_{\mathrm{qo}}^{\prime}(\mathrm{s})$ & 0.9 \\
\hline Time Constant $\mathrm{T}_{\mathrm{qo}} \mathrm{(s)}$ & 0.04 \\
\hline Total inertia H (s) & 1.05 \\
\hline Nominal frequency $(\mathrm{Hz})$ & 50 \\
\hline
\end{tabular}




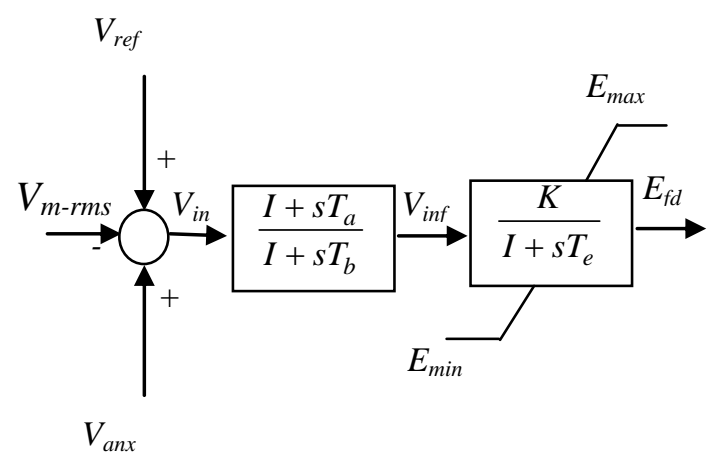

Fig. 2: Exciter System Model

The governor system related to the gas turbine including horizontal slope of $5 \%$ and the time constant of 0.2 second. The turbine model is a transformation function with the time constant of 0.3 seconds. The synchronous machine is equipped with the secondary frequency control system with the time constant of 4 seconds. Figure 3 shows the governor and turbine systems and the secondary frequency control loop.

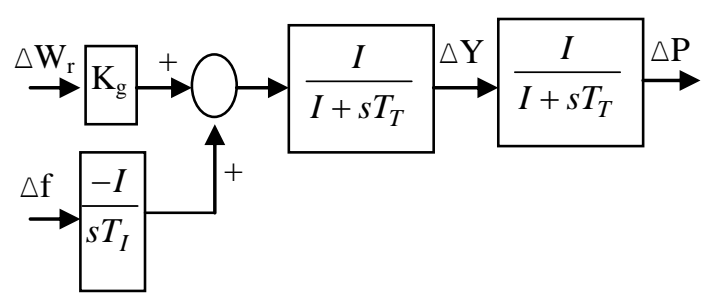

Fig. 3: Governor and Turbine Systems and the Secondary Frequency Control Loop

\subsection{Model of Power Electronic Based Distributed Generation (PE-DG)}

These groups of distributed generation resource are the resources that have the dc output and are connected to the power network through a power electronic converter. These resources can have energy reserving resources on dc side of their converter resources. From the bus dynamic, the dc distributed generation resource is not considered and is regarded as a constant dc voltage resource. The ac side, as shown in Figure 4, is connected to the network via a series RL circuit [10].

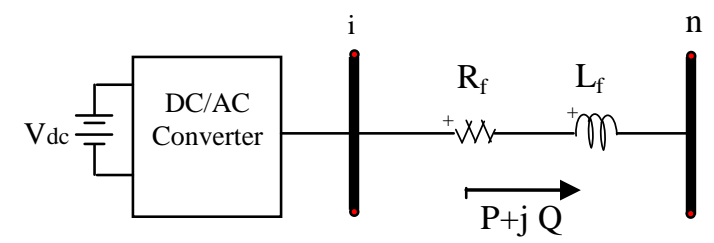

Fig. 4: Single-Line Connection Distributed Generation Resources with PE-DG

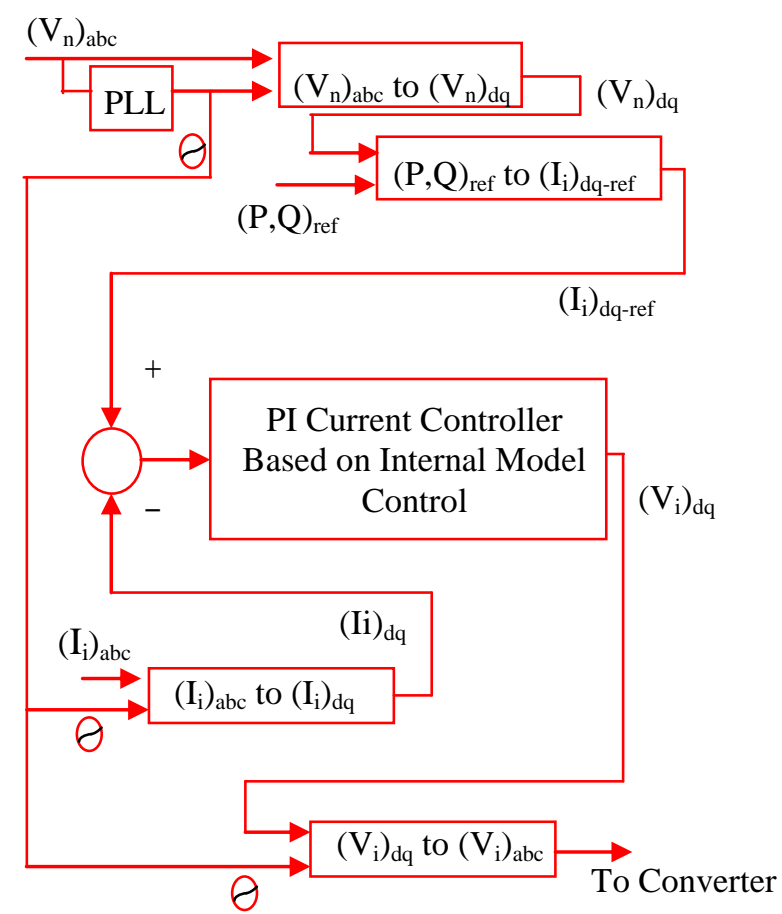

Fig. 5: Show How the Control of Power Active and Reactive of PEDG

The active and reactive control power in this distributed generation resource is based on the current control process. Figure 5 shows the schematic controlling of the active and reactive power. The data related to the distributed generation resources by the power electronic are given in Table 3.

Table 3: Data of Distributed Generation Resources with PE-DG

\begin{tabular}{|c|c|c|}
\hline parameter & $\mathrm{DG}_{1}$ & $\mathrm{DG}_{2}$ \\
\hline Nominal power (MVA) & 2.2 & 1.2 \\
\hline Nominal voltage $(\mathrm{kV})$ & 4.16 & 4.16 \\
\hline Resistance $\mathrm{R}_{\mathrm{f}}(\mathrm{pu})$ & 0.007 & 0.007 \\
\hline Inductance $\mathrm{X}_{\mathrm{f}}(\mathrm{pu})$ & 0.12 & 0.12 \\
\hline Frequency $(\mathrm{Hz})$ & 50 & 50 \\
\hline
\end{tabular}

\subsubsection{Strategy of generated active and reactive power of the distributed generation resources with $P E$ - DG with communication data}

In a grid with communication system, the amount of consumed active and reactive powers of the loading points are measured and sent to a controlling center, then the generated power in the existing resources in the microgrid will be calculated using (1), (2), and will be sent to distributed generation resources with PE-DG. Of course, such an issue requires the fact that the system is enabled to transfer the data, which would not be a complicated matter in microgrid and distributed generation resources. 


$$
\begin{aligned}
& \left(P_{g}\right)_{D G_{k}}=\left(\sum_{i=0}^{n} P_{l_{i}}\right) *\left(\frac{S_{D G_{k}}}{\sum_{j=0}^{m} S_{D G_{j}}}\right) \\
& \left(Q_{g}\right)_{D G_{k}}=\left(\sum_{i=0}^{n} Q_{l_{i}}\right) *\left(\frac{S_{D G_{k}}}{\sum_{j=0}^{m} S_{D G_{j}}}\right)
\end{aligned}
$$

$\left(P_{g}\right)_{D G_{k}}$ and $\left(Q_{g}\right)_{D G_{k}}$ is the generated active and reactive power of the distributed generation $k$ th resources with the PE-DG after the entrance of the $n$th load and the $S_{D G_{j}}$ is the optimal power of the $j$ th distributed generation resources. Based on (1), (2), the two PE-DG which shoulder the load supply in the microgrid which are proportionate with the nominal capacity and the remaining load will be rested on the synchronous generator, which is related to its capacity. Its active and reactive power generation would be based on local information.

\subsubsection{Strategy of generating active and reactive power of the distributed generation resources with PE-DG (power electronic converter based DG) with local data}

In the control approach based on the local data, the amounts of the needed active power that are produced by PE-DG are determined based on the droop curve of "active power - frequency". In addition, the amount of the needed reactive power is determined based on the droop curve of "reactive power - voltage". This concept is shown in Figure 6.
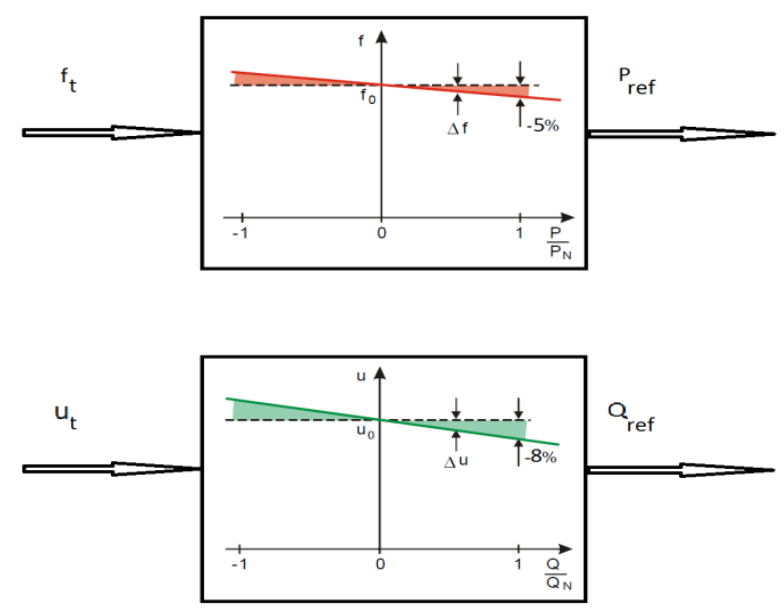

Fig. 6: The Amount of Active and Reactive Power Generated by Distributed Generation Resources with PE-DG with Local Information

\subsection{Load Modeling}

Currently, the electrical power industry has grown rapidly and loads are changing from simple, non- electronic loads such as tungsten lamps, motors, relays and resistive heaters to electronic ones such as fluorescent lamps, motors with solid-state drivers and industrial drives [11]. This study uses different kinds of loads to study different possible conditions. The loads of $\mathrm{L}_{2}, \mathrm{~L}_{3}, \mathrm{~L}_{5}$ and $\mathrm{L}_{6}$ include $37.44 \%, 22.19 \%, 33.21 \%$ and $51.06 \%$ motor loads, and the rest are RLC loads, respectively. The motor loads are connected to the main feeder through a cumulative transformer. The data related to the motor loads is given in Table 4 .

Table 4: Typical 150 HP Double-Cage Induction Motor Data

\begin{tabular}{|c|c|c|c|}
\hline $\begin{array}{c}\text { Parameters Of } \\
\text { Uivalent Circuit }\end{array}$ & Data & Motor Specification & Data \\
\hline $\mathrm{R}_{\mathrm{s}}(\mathrm{pu})$ & 0.0425 & Full-load efficiency & 0.9151 \\
\hline $\mathrm{X}_{\mathrm{s}-\mathrm{u}}(\mathrm{pu})$ & 0.0435 & Full-load power factor & 0.8895 \\
\hline $\mathrm{X}_{\mathrm{s}-\mathrm{s}}(\mathrm{pu})$ & 0.0435 & Full-load slip & 0.0166 \\
\hline $\mathrm{X}_{\mathrm{m}}(\mathrm{pu})$ & 2.9745 & No-load loss $(\mathrm{kW})$ & 2.594 \\
\hline $\mathrm{R}_{1}(\mathrm{pu})$ & 0.0739 & Starting current $(\mathrm{pu})$ & 6.4961 \\
\hline $\mathrm{X}_{\mathrm{r}-\mathrm{u}}(\mathrm{pu})$ & 0.0329 & Starting torque ratio & 1.5961 \\
\hline $\mathrm{X}_{\mathrm{r}-\mathrm{s}}(\mathrm{pu})$ & 0.0329 & Pull-out torque & 2.650 \\
\hline $\mathrm{R}_{2}(\mathrm{pu})$ & 0.0249 & Pull-out slip & 0.0914 \\
\hline $\mathrm{X}_{2}(\mathrm{pu})$ & 0.0739 & KVA rating & 137 \\
\hline $\mathrm{H}_{(\mathrm{pu})}$ & 0.6 & Rated voltage $(\mathrm{V})$ & 400 \\
\hline $\mathrm{I}_{\mathrm{sat}}(\mathrm{pu})$ & 3 & Rated current $(\mathrm{A})$ & 198 \\
\hline $\mathrm{I}_{\mathrm{sat}}(\mathrm{pu})$ & 3 & Load torque exponent & 2 \\
\hline
\end{tabular}

The $\mathrm{L}_{7}$ and $\mathrm{L}_{\mathrm{DG} 1}$ are commercial loads and $\mathrm{L}_{1}$ and $\mathrm{L}_{\mathrm{DG} 3}$ are the residential loads in the summer. Table 5 shows the relation proportion of the residential and commercial to the voltage and frequency.

The RLC model is used for the $\mathrm{L}_{4}$ and $\mathrm{L}_{\mathrm{DG} 1}$.

Table 5: Load Classes

\begin{tabular}{|c|c|c|c|c|}
\hline Load class & $\boldsymbol{\delta P} / \boldsymbol{\delta V}$ & $\boldsymbol{\delta Q} / \boldsymbol{\delta V}$ & $\boldsymbol{\delta P} / \boldsymbol{\delta f}$ & $\boldsymbol{\delta Q} / \boldsymbol{\delta f}$ \\
\hline Residential summer & 1.2 & 2.9 & 0.8 & -2.2 \\
\hline Commercial summer & 0.99 & 3.5 & 1.2 & -1.6 \\
\hline
\end{tabular}

\subsection{Load Switching}

The load switching should be done in the way that the voltage and frequency of the microgrid do not go beyond its limits. In this paper two different methods are used. The first method is using time constant and the second method, which is proposed for first time, is based on automatic switching.

\section{D.1. The time constant load switching}

The time constant load switching, considering the load average range, inserts each load into the main grid 
at a specific time interval. For example, the loads will enter the circuit at the time interval of 3 seconds.

\section{D.2. Automatic load switching}

In automatic load switching after each load entrance into the circuit and the frequency returning to its optimal condition, the next load will enter the circuit. Figure 7 shows the load automatic switching.

$S_{n}$ is the switching order of the load $L_{n}$ and $S_{n}=1$ means the entrance of the load $\mathrm{L}_{\mathrm{n}}$. Since the microgrid voltage and frequency are at their limited range before the load entrance, there would be no problem for the first load entrance.

$f_{t}$ is the microgrid frequency and $f_{\text {set }}$ is the predetermined frequency which is considered to be $49.9 \mathrm{~Hz}$ for this study. Each time after the load entrance into the circuit the frequency reaches the given point, the condition would be ready for the next load entrance.

The $f_{t}-f_{t-T} \geq 0$ condition will stop the load switching because of the low frequency range ( $\mathrm{T}$ is a period cycle).

Secondary orders which include the disconnecting and connecting the loads by the operator or the system will be applied in action.

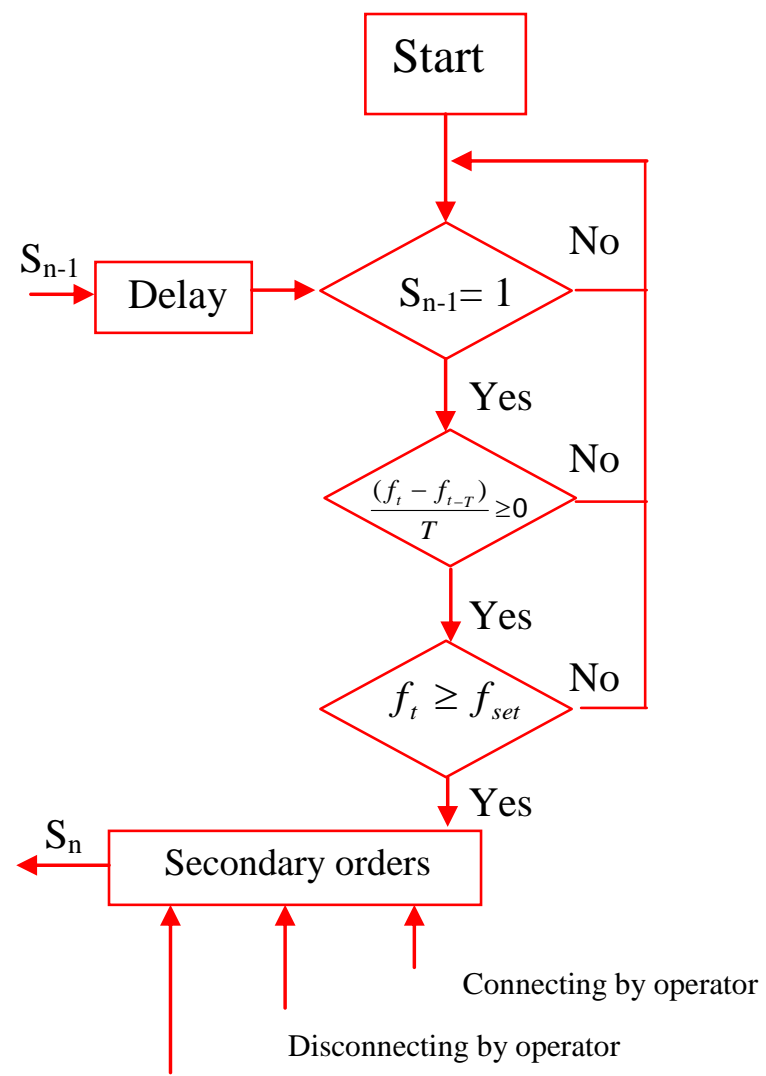

Disconnecting by system

Fig. 7: The Flowchart of Automatic Load Switching

\section{Simulation and Case Study}

Whenever a fault occurs in the main grid, the breaker number $1\left(\mathrm{CB}_{1}\right.$ in Figure 1$)$ will start operating, when the switches of 2 and 3 are open, the microgrid will be formed and coincidently the distributed generation resource will be sent out of the circuit, afterward, in order to restore the microgrid, the distributed generation resource $\left(\mathrm{t}_{\mathrm{DG} 1}=0.2 \mathrm{~s}, \mathrm{t}_{\mathrm{DG} 2}=0.1 \mathrm{~s}\right.$, $\mathrm{t}_{\mathrm{DG} 3}=0 \mathrm{~s}$ ) will be entered at a specific time.

First load will enter at $1 \mathrm{~s}$ and the next load will be after frequency optimal condition reaching $49.9 \mathrm{HZ}$. The priority of the loads will be their importance and the most important loads will enter first to face few cases of power cut. The loads that paid for the electricity with a higher reliability should enter the circuit sooner; of course the acceleration for the load entrance which is connected to the resource bus can have the higher priority. The priority order for the system under study would be as follows (Table.6):

Table 6: Priorities of loads

\begin{tabular}{|c|c|c|c|c|c|}
\hline Priority & 1 & 2 & 3 & 4 & 5 \\
\hline Load name & $\mathrm{L}_{\mathrm{DG} 3}$ & $\mathrm{~L}_{\mathrm{DG} 1}$ & $\mathrm{~L}_{\mathrm{DG} 2}$ & $\mathrm{~L}_{3}$ & $\mathrm{~L}_{1}$ \\
\hline \hline Priority & 6 & 7 & 8 & 9 & 10 \\
\hline Load name & $\mathrm{L}_{2}$ & $\mathrm{~L}_{4}$ & $\mathrm{~L}_{5}$ & $\mathrm{~L}_{6}$ & $\mathrm{~L}_{7}$ \\
\hline
\end{tabular}

Figure 8 and Figure 9 show the microgrid frequency in the restoring process for both conditions. Figure 10 and Figure 11 show magnitude of active and reactive power generated by distributed generation resources for restoration in the both condition. As it can be seen regarding the quick response of the distributed generation resources with PE-DG, the frequency is at the standard range (based on the IEEE 1547 standard).

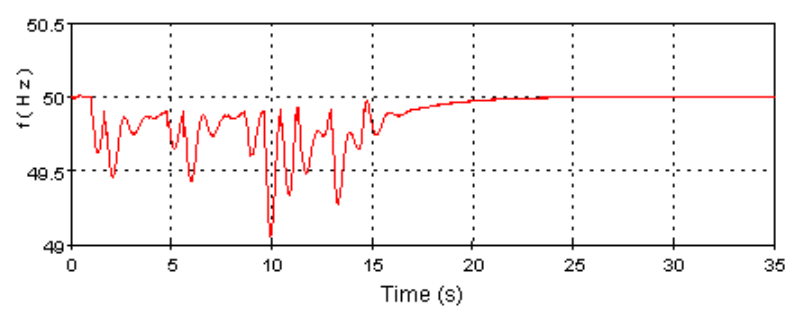

Fig. 8: Microgrid Frequency in Restoring Process for Communication Data and Automatic Load Switching

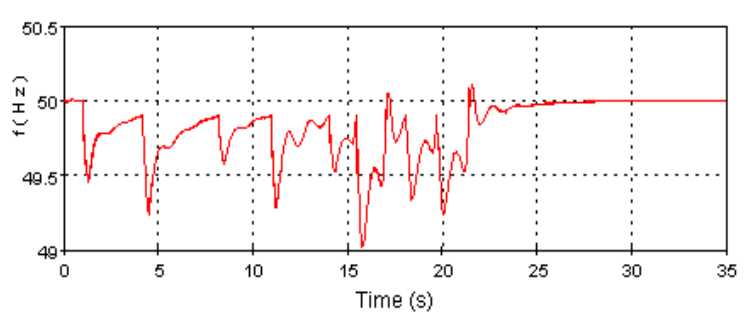

Fig. 9: Microgrid Frequency in Restoring Process for Local Data and Automatic Load Switching 
The existing difference of the frequency return in Figure 8 and Figure 9 is because of the controlling procedures for the active and reactive distributed generation resources with PE-DG.
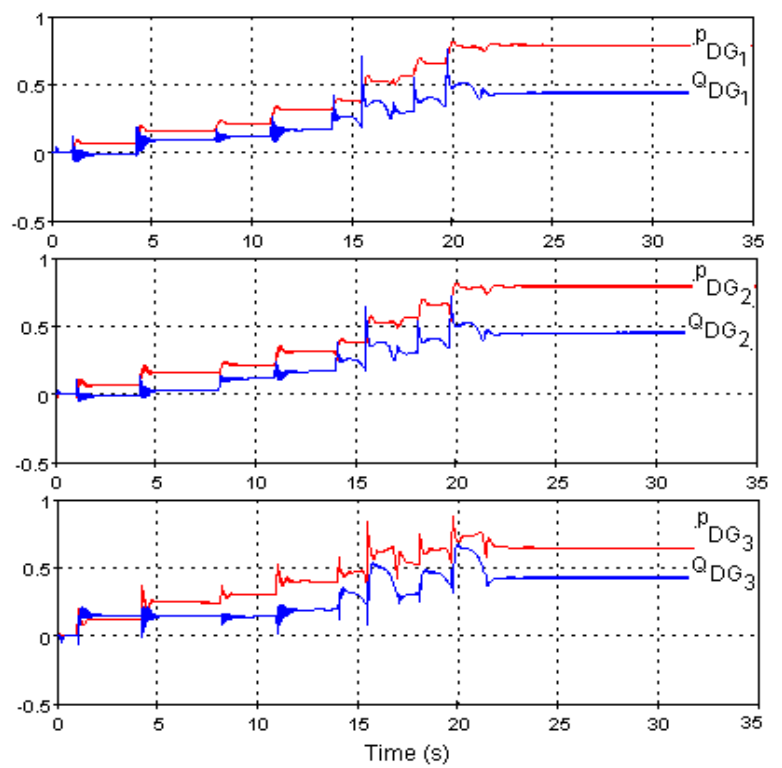

Fig. 10: Power Generated by Distributed Generation Resources in Restoring Process for Local Information and Automatic Load Switching in pu.
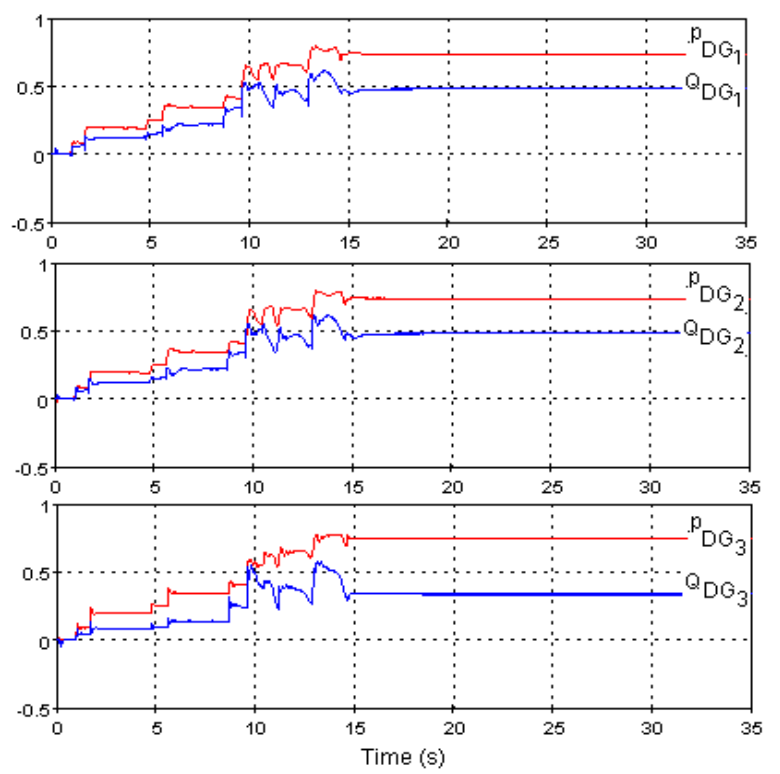

Fig. 11: Power Generated by Distributed Generation Resources in Restoring Process for Communication Data and Automatic Load Switching in pu.

Figure 12 and Figure 13 show the voltages of bus 7. Because of the bus 7 is the bus with the highest fall in the microgrid and its voltage is in the standard range for both conditions, all other buses have better condition. Figure 14 shows all the buses voltages, after restoring.

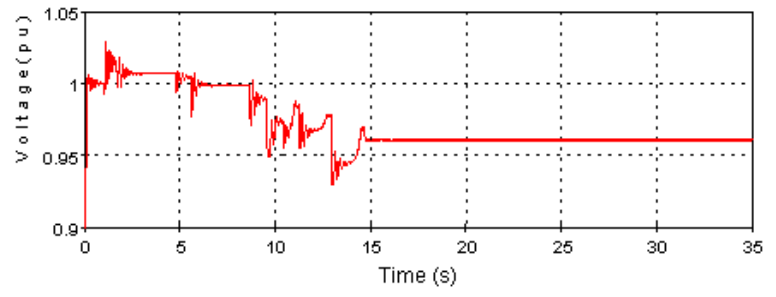

Fig. 12: Bus 7 Voltage in Microgrid Restoring Process for Communication Data and Automatic Load Switching

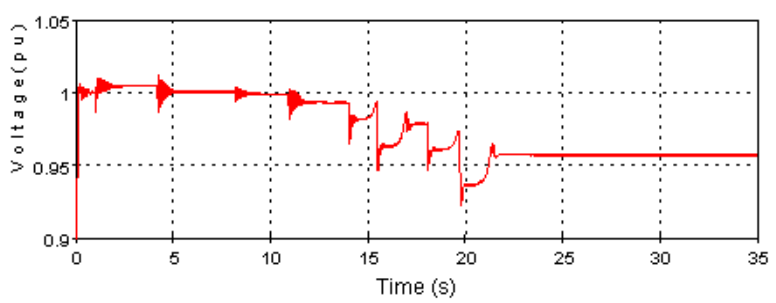

Fig. 13: Bus 7 Voltage in Microgrid Restoring Process for Local Data and Automatic Load Switching

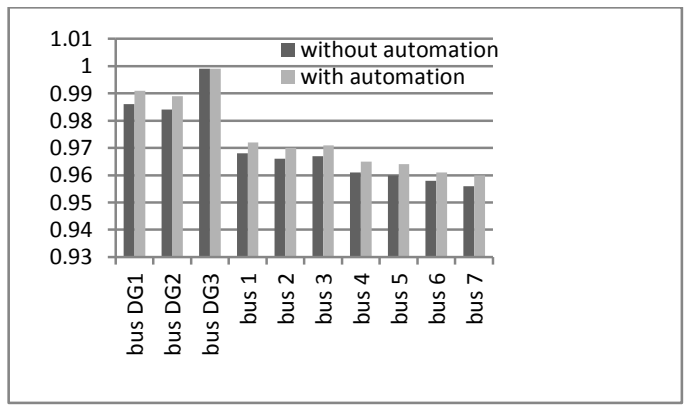

Fig. 14: Bus Voltage Microgrid After Being Restored (pu)

As it can be seen the frequency fluctuations for both restorations are similar, but the time for the restoration based on the local data is bigger than the restoration based on the communication data.

If the energy-not-supplied amount (ENS) is considered for both restoration conditions, we have the ENS amount for restoration with communication data and automatic load switching:

$$
E N S_{P \text {-aut }}=34.79 \mathrm{MWs}(\text { Mega Joule })
$$

The ENS amount for restoration with local data and automatic load switching:

$$
E N S_{\text {L-aut }}=56.92 \mathrm{MWs}(\text { Mega Joule })
$$

As it can be observed, the communication causes the reduction in ENS amount in microgrid to $38.89 \%$ for restoring process.

Now in order to provide a comparison, for both conditions the time constant switching method is considered. In the time constant load switching, the time constant for switching should be 3.113 seconds that is the difference between the $\mathrm{L}_{2}$ and $\mathrm{L}_{3}$ switching 
at the automatic condition of which the highest difference is related to two sequential switching.

Figure 15 shows the microgrid frequency in the restoring process with the communication data based on the time constant load switching method.

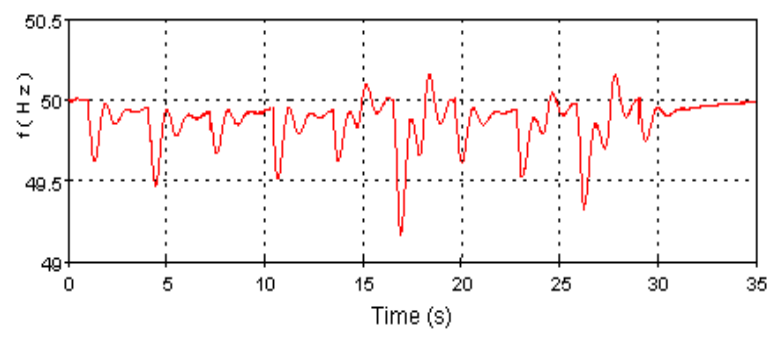

Fig. 15: Microgrid Frequency in Restoring Process for Communication Data with Constant Time Switching
If the energy-not-supplied amount (ENS) is considered for both restoration condition (communication data and local data) with constant time switching, we have:

The ENS amount for communication data with constant time switching:

$$
E N S_{P-c}=64.31 \mathrm{MWs}(\text { Mega Joule })
$$

The ENS amount for local data with constant time switching:

$$
E N S_{L-c}=82.57 \mathrm{MWs}(\text { Mega Joule })
$$

As it can be observed, the proposed automatic switching algorithm causes the reduction in ENS amount in microgrid to $45.9 \%$ for restoring process in communication condition. Table 7 shows ENS in different modes of microgrid restoration.

Table 7: The ENS in Different Modes of Microgrid Restoration

\begin{tabular}{|l|c|c|}
\hline \multicolumn{1}{|c|}{ Mode of microgrid restoration } & ENS (MWs) & Reducing ENS, if automatic switching and communication data are used \\
\hline Automatic switching and communication data & 34.79 & $0 \%$ \\
\hline Constant time switching and local data & 56.92 & $38.88 \%$ \\
\hline Automatic switching and communication data & 64.31 & $45.9 \%$ \\
\hline Constant time switching and local data & 82.57 & $58.02 \%$ \\
\hline
\end{tabular}

\section{Conclusions}

The results of the study show that using the different distributed generation resources (gas turbine, power electronic interfaced resources) and the proposed controlling algorithm for existing communication data and non-existing communication data, the microgrid parameters including the voltage and frequency were in the limited range of the IEEE 1547 standard and the microgrid is restored at the least time possible because of the load automatic switching. It should also be mentioned that the sensitive load faced minor power cuts that can add more values to the electricity price at the time of general power cut as well as the higher reliability that it would create.

\section{Appendix}

A. Line information

\begin{tabular}{|c|c|c|c|c|c|c|}
\hline Line & Brand & Nominal voltage & Superficies section & $\mathbf{R}_{\text {ac }}(\boldsymbol{\Omega} / \mathbf{k m})$ & $\mathbf{X}(\mathbf{\Omega} / \mathbf{k m})$ & Current limited \\
\hline 1 & Hyena & $20 \mathrm{KV}$ & $126 \mathrm{~mm}^{2}$ & 0.326 & 0.36 & $380 \mathrm{~A}$ \\
\hline 2 & AL-95 & $20 \mathrm{KV}$ & $95 \mathrm{~mm}^{2}$ & 0.35 & 0.364 & $295 \mathrm{~A}$ \\
\hline 3 & Mink & $20 \mathrm{KV}$ & $74 \mathrm{~mm}^{2}$ & 0.551 & 0.39 & $260 \mathrm{~A}$ \\
\hline 4 & Fax & $20 \mathrm{KV}$ & $43 \mathrm{~mm}^{2}$ & 0.95 & 0.414 & $190 \mathrm{~A}$ \\
\hline
\end{tabular}

B. Feeder information

\begin{tabular}{|c|c|c|c|}
\hline From bus & To Bus & Type of line & Length \\
\hline 1 & 2 & Line 1 & $1.75 \mathrm{Km}$ \\
\hline 2 & 3 & Line 2 & $1.5 \mathrm{Km}$ \\
\hline 2 & 4 & Line 3 & $1.6 \mathrm{Km}$ \\
\hline 4 & 5 & Line 3 & $2 \mathrm{Km}$ \\
\hline 4 & 6 & Line 4 & $1.5 \mathrm{Km}$ \\
\hline 6 & 7 & Line 4 & $1.6 \mathrm{Km}$ \\
\hline
\end{tabular}

C. Transformer information

\begin{tabular}{|c|c|c|c|}
\hline & $\begin{array}{c}\text { Trans. of } \\
\mathbf{D G}_{\mathbf{1}}\end{array}$ & $\begin{array}{c}\text { Trans. of } \\
\mathbf{D G}_{\mathbf{2}}\end{array}$ & $\begin{array}{c}\text { Trans. of } \\
\mathbf{D G}_{\mathbf{3}}\end{array}$ \\
\hline Nominal power(MVA) & 2.2 & 1.2 & 2 \\
\hline Nominal voltage(KV) & $4.16: 20$ & $0.69: 20$ & $11: 20$ \\
\hline $\mathrm{R}_{\mathrm{l}}(\mathrm{pu})$ & 0.008 & 0.01 & 0.01 \\
\hline $\mathrm{X}_{\mathrm{l}}(\mathrm{pu})$ & 0.065 & 0.045 & 0.06 \\
\hline $\mathrm{R}_{\mathrm{m}}(\mathrm{pu})$ & 600 & 600 & 650 \\
\hline $\mathrm{X}_{\mathrm{m}}(\mathrm{pu})$ & 300 & 300 & 300 \\
\hline
\end{tabular}




\section{References}

[1] Ye Robert H. Lasseter, Paolo Piagi, "Control and Design of Microgrid Components", Power Systems Engineering Research Center, PSERC Publication 06-03, January 2006.

[2] J. A. P.Lopes, C.L.Moreira, and A. G. Madureira, "Defining control strategies for MicroGrids landed operation," Power Systems, IEEE Transactions on, pp. 916-924, 2006.

[3] R. C. Dugan, T. F. McDermott, G. J. Ball, "Planning for Distributed Generation", IEEE Industry Application Magazine, March-April 2001.

[4] Tine Vandoorn, Bert Renders, Frederik De Belie, Bart Meersman and Lieven Vandevelde, "A Voltage-Source Inverter for Microgrid Applications with an Inner Current Control Loop and an Outer Voltage Control Loop", International Conference on Renewable Energies and Power Quality, Valencia (Spain), April 2009.

[5] IEEE Standards Coordinating Committee 21 "IEEE Standard for Interconnecting Distributed Resources with Electric Power Systems", IEEE Std. 1547'M , 2003.

[6] IEEE Standards Coordinating Committee 21 "IEEE Application Guide for IEEE Std. 1547TM, IEEE Standard for Interconnecting Distributed Resources with Electric Power Systems", IEEE Std. 1547.2 ${ }^{\mathrm{TM}}, 2008$.

[7] IEEE Standards Coordinating Committee 21 "IEEE Guide for Monitoring, Information Exchange, and Control of Distributed Resources Interconnected with Electric Power Systems", IEEE Std. 1547.3 ${ }^{\mathrm{TM}}, 2007$.

[8] IEEE Standards Coordinating Committee21 "IEEE Standard Conformance Test Procedures for Equipment Interconnecting Distributed Resources with Electric Power Systems", IEEE Std. 1547.1 $1^{\mathrm{TM}}, 2005$.

[9] P.Kundur, Power system stability and control, McGraw-Hill, Inc.1994.

[10] Z. Ye, R. Walling, L. Garces, R. Zhou, L. Li, T. Wang, Study and Development of Anti-Islanding Control for Grid-Connected Inverters, National Renewable Energy Laboratory, 2004.

[11] Adel Ashor Abosdeal, Ahmed Jaber Abougarir, "Design and Simulation of PFC Circuit for AC/DC Converter Based on PWM Boost Regulator", International Journal of Automation and Power Engineering, 2012.

\section{Authors' Profile}

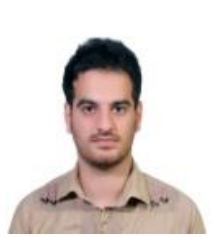

Elyas Zare $(1986-)$, Iran. He received the B.Sc. degree in power system engineering from Noshirvani University of Babol, Iran in 2009. He received the M.Sc. in the same field from Noshirvani University of Babol, Iran in 2012. His research directions include smart grids, microgrids and voltage stability in these systems.

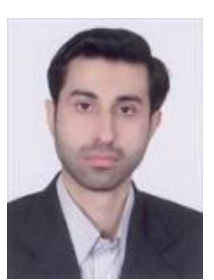

Majid Shahabi (1975-), he received the B.Sc (Electrical Engineering) and M.Sc. (Power Engineering) degrees from Tabriz University, Tabriz, Iran and Tarbiat Modarres University, Tehran, Iran in 1998 and 2001, respectively. He is currently pursuing the Ph.D. degree at Tarbiat Modarres University, Tehran, Iran. He is currently an assistant professor in power system engineering in Babol Noshirvani University of Technology, Iran .Also his field of interest is distribution system operation and control in presence of embedded generation resources. 